\title{
Zinc acetate lozenges reduced the duration and severity of symptoms of the common cold
}

Prasad AS, Fitzgerald JT, Bao B, et al. Duration of symptoms and plasma cytokine levels in patients with the common cold treated with zinc acetate. A randomized, double-blind, placebo-controlled trial. Ann Intern Med 2000 Aug $15 ; 133: 245-52$.

\section{QUESTION: In patients with a common cold, do zinc acetate lozenges reduce the duration and severity of symptoms?}

Design

Randomised (allocation concealed*), blinded (patients and outcome assessors),* placebo controlled trial with 12 days follow up.

\section{Setting}

Detroit Medical Center, Detroit, Michigan, USA.

\section{Patients}

50 volunteers (mean age $37 \mathrm{y}, 63 \%$ men) who were recruited within 24 hours of developing symptoms of the common cold and had $\geqslant 2$ of the following 10 symptoms: cough, headache, hoarseness, muscle ache, nasal drainage, nasal congestion, scratchy throat, sore throat, sneezing, or fever. Exclusion criteria were pregnancy, immunodeficiency disorder, chronic illness, or previous use of zinc lozenges to treat the common cold. 48 patients $(96 \%)$ completed the trial.

\section{Intervention}

25 patients were allocated to zinc lozenge, containing $12.8 \mathrm{mg}$ of zinc acetate to be taken every 2 to 3 hours while awake as long as they had cold symptoms. 23 patients were allocated to placebo to be taken in the same way as the zinc lozenges. All patients were instructed to take no other cold preparations during the study period.

\section{Main outcome measures}

The primary outcome was the average duration of cold symptoms. Secondary end points were plasma concentrations of zinc and pro-inflammatory cytokines.

\section{Main results}

Source of funding: in part, the George and Patsy Eby Research

Foundation.

For correspondence: Dr A S Prasad,

Department of

Medicine, Division of Hematology-Oncology,

Wayne State Universit)

University Health

Center 5-C, 4201 St

Antoine, Detroit, $M I$

48201, USA.Fax +1 3137454440 .
Mean overall duration of cold symptoms was shorter in the zinc group than in the placebo group (table). The specific symptoms that were of shorter duration in the zinc group were cough $(3.1 v 6.3 \mathrm{~d}, \mathrm{p}=0.001)$ and nasal discharge $(4.1 \approx 5.8 \mathrm{~d}, \mathrm{p}=0.025)$. Patients in the zinc group had decreased total severity scores for all symptoms $(2.7 \vee 5.4, \mathrm{p}=0.002)$. The difference in proinflammatory cytokine concentrations was greater in the zinc group than in the placebo group, but this difference was not significant. Plasma zinc concentration was higher in the zinc group (between group difference in mean change from baseline $3.7 \mu \mathrm{mol} / \mathrm{l}$, $95 \%$ CI 2.2 to 5.0 ).

\section{Conclusion}

In patients with a common cold, zinc acetate lozenges reduced the duration and severity of cold symptoms.

*See glossary.

Zinc acetate lozenge $v$ placebo for the common cold

\begin{tabular}{lccl} 
Outcome & Zinc & Placebo & $\begin{array}{l}\text { Mean difference } \\
(95 \% \mathrm{Cl}) \dagger\end{array}$ \\
$\begin{array}{c}\text { Duration of cold } \\
\text { symptoms }(\mathrm{d})\end{array}$ & 4.5 & 8.1 & $-3.6(-4.6$ to -2.6$)$ \\
\hline+ Cl calculated from data in article. & &
\end{tabular}

\section{COMMENTARY}

Evidence of the efficacy of treatments for the common cold is important given the morbidity and costs to society resulting from coryzal illness. Zinc has antiviral properties in vitro, and zinc lozenges were proposed to treat colds after the report of the trial by Eby et al in $1984 .{ }^{1}$ A recent meta-analysis suggests, however, that there is not enough evidence of efficacy and that any benefit will probably be modest. $^{2}$

The study by Prasad et al provides important additional evidence and suggests that zinc lozenges may provide benefit for both symptom duration and symptom severity. Nevertheless, several limitations are inherent in this study, particularly its size. The trial was underpowered to detect important apparent differences in blinding, ${ }^{3}$ which is especially difficult with zinc. The trial also uses a university volunteer sample, which makes the results difficult to extrapolate to routine settings. Furthermore, the benefit in terms of symptom severity is modest: by day 4 , the difference in scores was $<3$ (equivalent to 3 symptoms being rated mild rather than moderate out of a total of 10 symptoms) and most benefit occurred after day 4 when symptoms are mild. Large, adequately blinded trials in representative primary care settings are needed to establish more firmly the place of zinc in treatment of the common cold.

Paul Little, MP, MBBS University of Southampton Southampton, $U K$

1 Eby GA, Davis DR, Halcomb WW. Reduction in duration of common colds by zinc gluconate lozenges in a double-blind study. Antimicrob Agents Chemother 1984;25:20-4.

2 Marshall I. Zinc for the common cold. Cochrane Database Syst Rev 2000;(2):CD 001364.

3 Desbiens NA. Lessons learned from attempts to establish the blind in placebo-controlled trials of zinc for the common cold. Ann Intern Med 2000 Aug;133:302-3. 